\title{
Dengue score as a diagnostic predictor for pleural effusion and/or ascites: external validation and clinical application
}

\author{
Suhendro Suwarto ${ }^{1,2^{*}}$ D, Mohammad Jauharsyah Hidayat ${ }^{3}$ and Bing Widjaya ${ }^{4}$
}

\begin{abstract}
Background: The Dengue Score is a model for predicting pleural effusion and/or ascites and uses the hematocrit (Hct), albumin concentration, platelet count and aspartate aminotransferase (AST) ratio as independent variables. As this metric has not been validated, we conducted a study to validate the Dengue Score and assess its clinical application.

Methods: A retrospective study was performed at a private hospital in Jakarta, Indonesia. Patients with dengue infection hospitalized from January 2011 through March 2016 were included. The Dengue Score was calculated using four parameters: Hct increase $\geq 15.1 \%$, serum albumin $\leq 3.49 \mathrm{mg} / \mathrm{dL}$, platelet count $\leq 49,500 / \mu \mathrm{L}$ and AST ratio $\geq 2.51$. Each parameter was scored as 1 if present and 0 if absent. To validate the Dengue Score, goodness-of-fit was used to assess calibration, and the area under the receiver operating characteristic curve (AROC) was used to assess discrimination. Associations between clinical parameters and Dengue Score groups were determined by bivariate analysis.

Results: A total of 207 patients were included in this study. The calibration of the Dengue Score was acceptable (Hosmer-Lemeshow test, $p=0.11$ ), and the score's discriminative ability was good (AROC $=0.88$ (95\% Cl: 0.83-0.92)). At a cutoff of $\geq 2$, the Dengue Score had a positive predictive value (PPV) of $79.03 \%$ and a negative predictive value (NPV) of $90.36 \%$ for the diagnostic prediction of pleural effusion and/or ascites. Compared with the Dengue Score $\leq 1$ group, the Dengue Score $=2$ group was significantly associated with hemoconcentration $>20 \%(p=0.029)$, severe thrombocytopenia $(p=0.029)$, and increased length of hospital stay $(p=0.003)$. Compared with the Dengue Score $=2$ group, the Dengue Score $\geq 3$ group was significantly associated with hemoconcentration $>20 \%(p=0.001)$, severe thrombocytopenia $(p=0.024)$, severe dengue $(p=0.039)$, and increased length of hospital stay $(p=0.011)$.

Conclusion: The Dengue Score performed well and can be used in daily practice to help clinicians identify patients who have plasma leakage associated with severe dengue.
\end{abstract}

Keywords: Clinical application, Dengue score, External validation

\section{Background}

Identifying plasma leakages in patients with dengue, which is also known as dengue hemorrhagic fever (DHF), is essential for determining which patients are at high risk for developing severe dengue [1]. However, over-diagnosis results in unnecessary hospital admission [2]. According to World Health Organization criteria, plasma leakage is

\footnotetext{
* Correspondence: suhendro@ui.ac.id

${ }^{1}$ Tropical and Infectious Diseases Consultant, Pondok Indah Hospital, Jakarta, Indonesia

${ }^{2}$ Division of Tropical and Infectious Diseases, Department of Internal Medicine, Faculty of Medicine Universitas Indonesia, Cipto Mangunkusumo National Hospital, Jakarta, Indonesia

Full list of author information is available at the end of the article
}

defined as hematocrit (Hct) elevation of $\geq 20 \%$, hypoalbuminemia, and the presence of pleural effusion/ascites [3]. Recently, Suwarto et al. [4] developed criteria for diagnosing pleural effusion and/or ascites as a marker of plasma leakage which involves four diagnostic variables: hemoconcentration $\geq 15.1 \%$, albumin concentration $\leq 3.49 \mathrm{mg} / \mathrm{dL}$, platelet count $\leq 49,500 / \mu \mathrm{L}$, and aspartate aminotransferase (AST) ratio $\geq 2.51$. This diagnostic predictor is named the Dengue Score. This diagnostic prediction model has exhibited good calibration and discrimination [4]. The main differences between the Dengue Score and World Health Organization criteria are that the former has a lower hemoconcentration cutoff and includes two additional laboratory 
parameters (AST ratio and platelet count) as indicators of plasma leakage. Although this score may improve identifying plasma leakage in patients with dengue infection, it has not been validated. In fact, differences in patient characteristics could potentially influence this score's diagnostic predictions. Therefore, external validation is needed to confirm the extent of the metric's generalizability $[5,6]$.

One characteristic of an ideal scoring system is applicability in clinical practice [6]. In dengue-infected patients, plasma leakage is associated with hemoconcentration $\geq 20 \%$, severe thrombocytopenia, severe dengue, and increased length of stay (LOS) in the hospital. The first three variables significantly impact the management of dengue infection [7-9]. Therefore, we conducted a study to validate the Dengue Score and assess its clinical application in daily practice.

\section{Methods}

A retrospective study was conducted in the ward of Pondok Indah Hospital in Jakarta, Indonesia. Patients $\geq 14$ years of age with acute fever and a positive non-structural protein 1 (NS-1) antigen test (SD BIOLINE Dengue Duo, Standard Diagnostics, Korea) who were admitted to the hospital from January 2011 through March 2016 were included in this investigation. Data were obtained from each patient's medical records. The following clinical parameters were recorded: patient characteristics, hospital LOS, daily complete blood count, serum albumin, AST, and abdominal ultrasonography (USG) findings. The abdominal USG result was used to assess the presence or absence of pleural effusion and/or ascites. Serum albumin, AST, and abdominal USG examinations were performed 1-2 days after defervescence. Hct was calculated using published formulae [4]. The AST ratio was calculated by dividing the AST value by the upper bound of the reference range (which was $37 \mathrm{U} / \mathrm{L}$ in this investigation) [4]. Patients who were pregnant or had incomplete documentation were excluded.

The Dengue Score was calculated using four parameters: Hct increase $\geq 15.1 \%$, serum albumin $\leq 3.49 \mathrm{mg} / \mathrm{dL}$, platelet count $\leq 49,500 / \mu \mathrm{L}$ and AST ratio $\geq 2.51$. Each parameter was scored as 1 if present and 0 if absent [4]. Subjects were classified into three groups based on their Dengue Score: the Dengue Score $\leq 1$ group, the Dengue Score $=2$ group, and the Dengue Score $\geq 3$ group.

Severe thrombocytopenia was defined as a platelet count $<10,000 / \mu \mathrm{L}$ [8]. Severe dengue was defined as the presence of one of the following conditions: dengue shock syndrome (DSS), respiratory distress, severe bleeding, AST $\geq 1000 \mathrm{U} / \mathrm{L}$, or organ failure [7]. LOS was calculated by determining the interval between a patient's discharge and admission dates; values for LOS were classified into the categories of $\leq 5$ days and $>5$ days [9].

\section{Statistical analysis}

The sample size was based on the required sample size to externally validate a prognostic model, namely, a minimum of 100 events (in this study, event refers to patients with pleural effusion and/or ascites) [10]. Thus, the minimum total sample size for this study was 200 patients. The performance of the Dengue Score was assessed for calibration and discrimination.

\section{Calibration}

Calibration refers to the agreement between observed and expected outcomes (in this study, pleural effusion and/or ascites). Calibration was analyzed using the Hosmer-Lemeshow goodness-of-fit statistic, with $p>0.05$ considered indicative of a well-calibrated score.

\section{Discrimination}

The ability of the Dengue Score to discriminate between those with and without pleural effusion and/or ascites was assessed using the area under the receiver operating characteristic curve (AROC). AROC values $>0.8$ were regarded as indicative of good discrimination.

\section{Clinical application of dengue score}

The associations of clinical parameters (hemoconcentration $\geq 20 \%$, severe thrombocytopenia, severe dengue, and LOS) between the Dengue Score $\leq 1$ and Dengue Score $=2$ groups, between the Dengue Score $\leq 1$ and Dengue Score $\geq 3$ groups, and between the Dengue Score $=2$ and Dengue Score $\geq 3$ groups were analyzed using chisquare tests. All statistical analyses were performed using STATA, version 14.0 (StataCorp, College Station, TX, USA), and GraphPad Prism, version 7.00 for Windows (GraphPad Software, La Jolla, CA, USA).

\section{Results}

A total of 207 patients with dengue infection satisfied our inclusion criteria. Clinical characteristics of these patients are presented in Table 1. Median fever onset of the patients on the admission day was 3 (Interquartile range [IQR], 2-4). Table 2 shows a comparison of fever onset and the clinical parameters of the Dengue Score for each study group.

\section{Performance of the dengue score}

The Hosmer-Lemeshow test indicated that the Dengue Score exhibited good calibration $(p=0.11)$ (Fig. 1), and the AROC indicated that this metric had good accuracy (0.88; 95\% CI: 0.83-0.92)] (Fig. 2). With a cutoff of $\geq 2$, the Dengue Score had a sensitivity of $92.45 \%$, a specificity of $74.26 \%$, a positive predictive value (PPV) of $79.03 \%$, and 
Table 1 Patient characteristics and clinical parameters

\begin{tabular}{|c|c|}
\hline Characteristic & $\begin{array}{l}\text { Number of patients } \\
(N=207)\end{array}$ \\
\hline $\mathrm{Age}^{\mathrm{a}}$ & $33(23-46)$ \\
\hline \multicolumn{2}{|l|}{ Sex, n (\%) } \\
\hline Male & $91(44)$ \\
\hline Female & $116(56)$ \\
\hline \multicolumn{2}{|l|}{ Dengue score, n (\%) } \\
\hline 0 & 37 (17.9) \\
\hline 1 & $46(22.2)$ \\
\hline 2 & $38(18.4)$ \\
\hline 3 & $55(26.6)$ \\
\hline 4 & $31(15.0)$ \\
\hline \multicolumn{2}{|l|}{ Hemoconcentration, n (\%) } \\
\hline$\leq 20 \%$ & $172(83.1)$ \\
\hline$>20 \%$ & $35(16.9)$ \\
\hline \multicolumn{2}{|l|}{ Severe thrombocytopenia, n (\%) } \\
\hline$\geq 10,000 / \mu \mathrm{L}$ & $182(87.9)$ \\
\hline$<10,000 / \mu \mathrm{L}$ & $25(12.1)$ \\
\hline \multicolumn{2}{|l|}{ Severe dengue, n (\%) } \\
\hline AST $\geq 1000$ & $5(2.4)$ \\
\hline DSS & $4(1.9)$ \\
\hline Respiratory distress & $4(1.9)$ \\
\hline Severe bleeding & $3(1.4)$ \\
\hline Organ failure & $3(1.4)$ \\
\hline \multicolumn{2}{|l|}{ Length of stay, n (\%) } \\
\hline$\leq 5$ days & $101(48.8)$ \\
\hline$>5$ days & $106(51.2)$ \\
\hline \multicolumn{2}{|l|}{ Abdominal USG, n (\%) } \\
\hline Absence of pleural effusion and/or ascites & $101(48.8)$ \\
\hline Presence of pleural effusion and/or ascites & $106(51.2)$ \\
\hline
\end{tabular}

${ }^{\mathrm{a}}$ Data presented as median (interquartile range)

a negative predictive value (NPV) of $90.36 \%$; $83.57 \%$ of cases were correctly classified (Table 3 ).

\section{Clinical application}

Relative to the Dengue Score $\leq 1$ group, the Dengue Score $=2$ group was significantly associated with hemoconcentration $\geq 20 \%$ ( $p=0.029)$, severe thrombocytopenia $(\mathrm{p}=0.029)$, and increased LOS $(p=0.003)$. Relative to the Dengue Score $\leq 1$ group, the Dengue Score $\geq 3$ group was significantly associated with hemoconcentration $>20 \%$, severe thrombocytopenia, severe dengue, and increased LOS ( $p<0.001$ for each comparison). Finally, compared with the Dengue Score $=2$ group, the Dengue Score $\geq 3$ group was significantly associated with hemoconcentration> $20 \%(p=0.001)$, severe thrombocytopenia $(p=0.024)$, severe dengue $(p=0.039)$, and increased LOS $(p=0.011)$ (Table 4$)$.
Table 2 Comparison of patients with Dengue Score $\leq 1$, Dengue Score $=2$ and Dengue Score $\geq 3$

\begin{tabular}{|c|c|c|c|}
\hline & $\begin{array}{l}\text { Dengue Score } \leq 1 \\
(N=83)\end{array}$ & $\begin{array}{l}\text { Dengue } \\
\text { Score = } 2 \\
(N=38)\end{array}$ & $\begin{array}{l}\text { Dengue } \\
\text { Score } \geq 3 \\
(N=86)\end{array}$ \\
\hline Fever onset, days $^{a}$ & $3(2-4)$ & $2.5(2-4)$ & $3(2-3)$ \\
\hline \multicolumn{4}{|c|}{ Hemoconcentration $\geq 15.1 \%$, n (\%) } \\
\hline Negative & $83(100 \%)$ & $31(81.6)$ & $36(41.9)$ \\
\hline Positive & $0(0 \%)$ & $7(18.4)$ & $50(58.1)$ \\
\hline \multicolumn{4}{|c|}{ Serum albumin $\leq 3.49 \mathrm{mg} / \mathrm{dL}, \mathrm{n}(\%)$} \\
\hline Negative & $68(81.9)$ & $21(55.3)$ & $8(9.3)$ \\
\hline Positive & $15(18.1)$ & $17(44.7)$ & $78(90.7)$ \\
\hline \multicolumn{4}{|c|}{ Platelet count $\leq 49,500, \mathrm{n}(\%)$} \\
\hline Negative & $69(83.1)$ & $10(26.3)$ & $2(2.3)$ \\
\hline Positive & $14(16.9)$ & $28(73.7)$ & $84(97.7)$ \\
\hline \multicolumn{4}{|c|}{ AST ratio $\geq 2.51, \mathrm{n}(\%)$} \\
\hline Negative & $66(79.5)$ & $14(36.8)$ & $9(10.5)$ \\
\hline Positive & $17(20.5)$ & $24(63.2)$ & $77(89.5)$ \\
\hline
\end{tabular}

\section{Discussion}

In this study, the Dengue Score was validated using an external data set. The laboratory parameters, i.e., levels of AST, serum albumin and USG, were assessed in the critical phase. The degree of hemoconcentration and the lowest platelet count were determined based on daily complete blood count measurement. A previous study reported that an elevated AST level, a lower albumin concentration, the hematocrit peak, the lowest platelet count, and increased detectable of pleural effusion/ascites by USG were found in the critical phase or 1-2 days after defervescence $[4,11,12]$. In addition, the degree of hemoconcentration can be calculated by using the minimum hematocrit during admission or the hematocrit at convalescence as a reference [12]. In addition, a cut-off point for platelet count $<50,000 / \mu \mathrm{L}$ and serum albumin $<$ $3.5 \mathrm{~g} / \mathrm{dL}$ are widely used as indicators of plasma leakage $[13,14]$. Furthermore, using the degree of hemoconcentration and AST ratio will resolve the problem of differences in reference limits among laboratories. Therefore, these laboratory parameter cut-off points can be used universally in various laboratories $[4,12]$.

Performance analysis of the Dengue Score using the Hosmer-Lemeshow test produced nonsignificant results, indicating that the score is well calibrated; this metric has good discriminative ability, as revealed by an AROC $>0.8$. When a cutoff of $\geq 2$ was used, the Dengue Score exhibited higher sensitivity $(92.45 \%$ vs $82.47 \%)$ and similar specificity $(74.26 \%$ vs $70.42 \%)$ to that reported in a prior study [4]. In addition, compared with our previous investigation, this study found a higher NPV (90.36\% vs $74.63 \%)$ and a similar PPV (79.03\% vs 
Hosmer-Lemeshow test, $p=0.11$

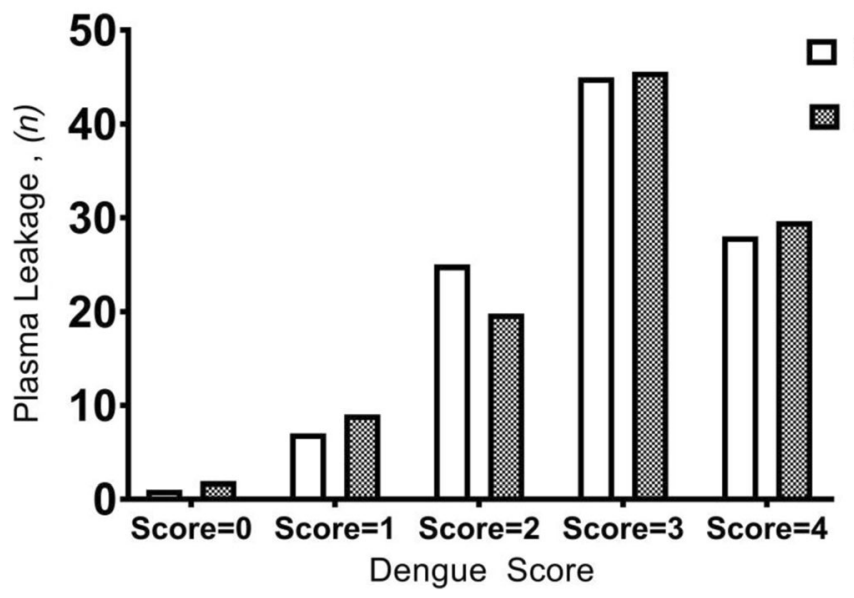

Fig. 1 Calibration of the Dengue Score: Observed and expected pleural effusion and/or ascites $(N=207)$

79.21\%) for the Dengue Score [4]. A score with high sensitivity is useful for screening to identify a disease, and a negative result can be useful to exclude a disease (in this case, plasma leakage or DHF) $[15,16]$. Our findings are consistent with clinical parameters demonstrating that patients with a Dengue Score $\leq 1$ did not develop hemoconcentration $>20 \%$, severe thrombocytopenia, or severe dengue. Therefore, patients with Dengue Score $\leq 1$ are likely to have dengue fever (DF), the mildest form of dengue infection.

Clinical parameter analyses demonstrated that compared with the Dengue Score $\leq 1$ group, the Dengue Score $=2$ group was significantly associated with hemoconcentration $\geq 20 \%$, severe thrombocytopenia, and increased LOS. Hematocrit increases of $20 \%$ or more are regarded as indicative of increased vascular permeability, which can result in plasma leakage and hypovolemia [7]. Dengue-infected patients with a rise in hemoconcentration $\geq 20 \%$ should immediately receive intravenous fluids $[3,7]$. Prior studies have indicated that degree of thrombocytopenia correlated with severity of plasma leakage and length of hospital stay [3, 9, 17]. Another study reported that the proportion of patients with severe thrombocytopenia was significantly higher in DHF group compare to DF group (42.9\% vs 0\%) [18]. Previous findings and our clinical parameter analysis results support the diagnostic prediction that patients with a Dengue Score $=2$ have a high probability of

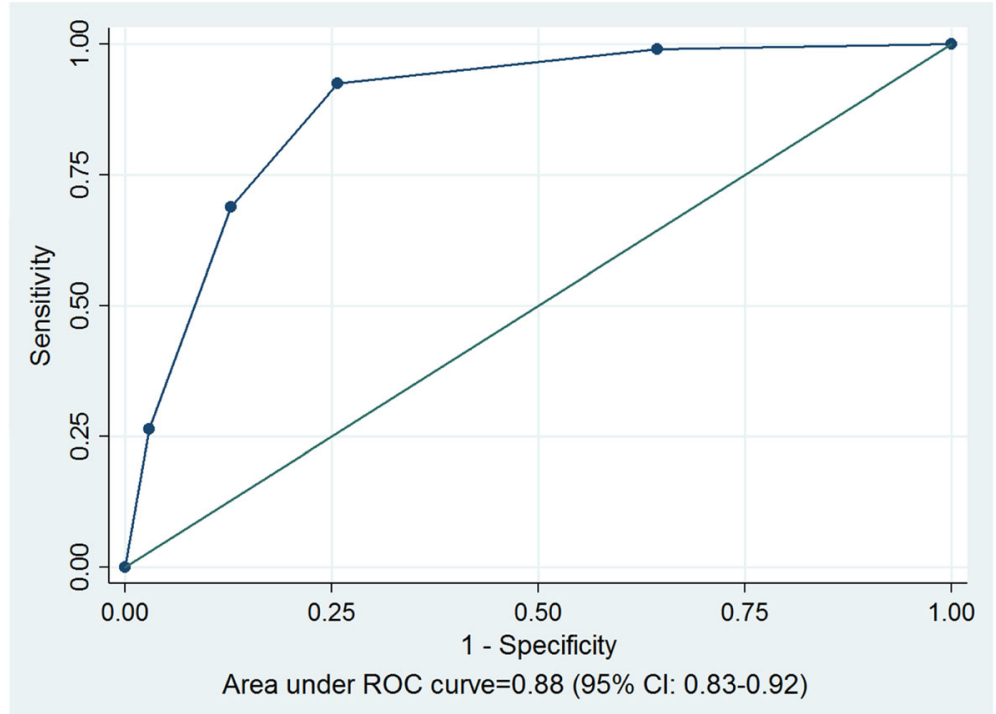

Fig. 2 Area under the receiver operating characteristic (AROC) of the Dengue Score 
Table 3 Sensitivity and specificity of different Dengue Score cutoff points

\begin{tabular}{llllll}
\hline Cutoff score & Sensitivity & Specificity & $\begin{array}{l}\text { Positive } \\
\text { predictive } \\
\text { value }\end{array}$ & $\begin{array}{l}\text { Negative } \\
\text { predictive } \\
\text { value }\end{array}$ & $\begin{array}{l}\text { Correctly } \\
\text { classified }\end{array}$ \\
\hline$\geq 1$ & $99.06 \%$ & $35.64 \%$ & $61.76 \%$ & $97.30 \%$ & $68.12 \%$ \\
$\geq 2$ & $92.45 \%$ & $74.26 \%$ & $79.03 \%$ & $90.36 \%$ & $83.57 \%$ \\
$\geq 3$ & $68.87 \%$ & $87.13 \%$ & $84.88 \%$ & $72.73 \%$ & $77.78 \%$ \\
$\geq 4$ & $26.42 \%$ & $97.03 \%$ & $90.32 \%$ & $55.68 \%$ & $60.87 \%$ \\
\hline
\end{tabular}

plasma leakage and may therefore should be closely observed in health care facilities.

We also found that relative to the Dengue Score $\leq 1$ and $=2$ group, the Dengue Score $\geq 3$ group was significantly associated with hemoconcentration $>20 \%$, severe thrombocytopenia, severe dengue, and increased LOS. A previous study revealed that $90 \%$ of DSS group subjects had hemoconcentration $>20 \%$ compared to $67 \%$ in DHF group subjects [19]. This finding was in accordance with another study reporting a significantly higher proportion of hemoconcentration $>20 \%$ in a severe dengue group compared to a non-severe dengue group [12]. Fernando et al. [20] reported that the proportion of severe thrombocytopenia patients was significantly higher in severe dengue group compare to non-severe dengue group (68.18\% vs $3.03 \%)$. In addition, severe thrombocytopenia was significantly associated with the development of severe dengue [21]. These findings may explain the higher proportion of hemoconcentration $>20 \%$ and severe thrombocytopenia in the Dengue Score $\geq 3$ group relative to the Dengue Score $\leq 1$

Table 4 Associations between clinical parameters and Dengue Score groups

\begin{tabular}{|c|c|c|c|}
\hline & $\begin{array}{l}\text { Dengue } \\
\text { Score } \leq 1\end{array}$ & $\begin{array}{l}\text { Dengue } \\
\text { Score }=2\end{array}$ & $\begin{array}{l}\text { Dengue } \\
\text { Score } \geq 3\end{array}$ \\
\hline \multicolumn{4}{|c|}{ Hemoconcentration, n (\%) } \\
\hline$\leq 20 \%$ & $83(100)$ & $35(92.1)^{\mathrm{a}}$ & $54(62.8)^{a, b}$ \\
\hline$>20 \%$ & $0(0)$ & $3(7.9)$ & $32(37.2)$ \\
\hline \multicolumn{4}{|c|}{ Severe thrombocytopenia, n (\%) } \\
\hline$\geq 10,000 / \mu \mathrm{L}$ & $83(100)$ & $35(92.1)^{\mathrm{a}}$ & $64(74.4)^{a, b}$ \\
\hline$<10,000 / \mu \mathrm{L}$ & $0(0)$ & $3(7.9)$ & $22(25.6)$ \\
\hline \multicolumn{4}{|c|}{ Severe dengue, n (\%) } \\
\hline Negative & $83(100)$ & $36(94.7)$ & $69(80.2)^{a, b}$ \\
\hline Positive & $0(0)$ & $2(5.3)$ & $17(19.8)$ \\
\hline \multicolumn{4}{|c|}{ Length of stay, n (\%) } \\
\hline$\leq 5$ days & $62(74.7)$ & $18(47.4)^{a}$ & $21(24.4)^{a, b}$ \\
\hline$>5$ days & $21(25.3)$ & $20(52.6)$ & 65 (75.6) \\
\hline
\end{tabular}

Data are presented as number of patients (\%) for each group. Chi-square tests were used to assess associations between findings for two groups. ${ }^{a}$ a significant association relative to the Dengue Score $\leq 1$ group; $^{\mathrm{b}}$ a significant association relative to the Dengue Score $=2$ group $(p<0.05)$ and $=2$ group due to a significantly higher proportion of severe dengue in the former.

Hypoalbuminemia, one parameter of the Dengue Score, has been reported to be a cause of fluid accumulation, and this condition could be used as a surrogate marker for severe plasma leakage [22, 23]. Thein et al. [24] reported that a combination of three variables, i.e., hemoconcentration, rapid decrease in platelet count, and fluid accumulation, had high specificity for predicting severe dengue. Trung et al. [25] demonstrated elevated AST levels to be correlated with disease severity, as indicated by manifestations such as vascular leakage and bleeding. Another study reported that elevated AST concurrent with hypoalbuminemia and hemoconcentration concurrent with thrombocytopenia could be used to identify severe dengue [26]. In addition, a study of dengue patients hospitalized between 2008 and 2013 showed that a combination of three variables, namely, fluid accumulation, elevated AST level and thrombocytopenia, were associated with severe dengue [27], and a meta-analysis study reported that four laboratory parameter variables, hemoconcentration, hypoalbuminemia, elevated AST level and thrombocytopenia, were significantly associated with DSS [28]. These prior findings may explain why the group of subjects with a minimum combination of three factors among hemoconcentration, hypoalbuminemia, thrombocytopenia and elevated AST ratio, that is, the Dengue Score $\geq 3$ group, was more closely associated with severe dengue and prolonged hospital stay than the Dengue Score $\leq 1$ and $=2$ group.

This study has a limitation. It used a retrospective design, and there was therefore the potential for bias in data collection. We only included patients with complete data, which we defined as including abdominal USG findings. Therefore, the study subjects may have represented a relatively ill patient population.

\section{Conclusions}

As a diagnostic predictor of pleural effusion and/or ascites, the Dengue Score is well calibrated and exhibits good discrimination. The application of this simple scoring system, which comprises laboratory parameters that are routinely measured in clinical practice, may help clinicians identify patients with plasma leakage associated with severe dengue.

\footnotetext{
Abbreviations

AROC: area under the receiver operating characteristic curve; AST: aspartate aminotransferase; DF: dengue fever; DHF: dengue hemorrhagic fever; DSS: dengue shock syndrome; Hct: hematocrit; LOS: length of stay; NPV: negative predictive value; NS-1: non-structural protein 1; PPV: positive predictive value; USG: ultrasonography
}

\section{Acknowledgments}

The authors would like to thank Surya Ulhaq, MD, and Bayu Kresna, S Kom, $\mathrm{MM}$, for assisting with the data collection and management. 


\section{Funding}

This study was supported by an internal grant from Pondok Indah Hospital in Jakarta, Indonesia.

\section{Availability of data and materials}

The raw data of this study are owned by Pondok Indah Hospital Jakarta, Indonesia, and will not to be shared to ensure patient anonymity. Data are however available from the authors upon reasonable request and permission by Pondok Indah Hospital.

\section{Authors' contributions}

Concept and design of the study: SS, MJH, BW. Statistical analysis: SS, MJH. Drafted the manuscript: SS, MJH, BW. Critically revised the manuscript for important intellectual content: SS, MJH, BW. Final approval of the manuscript to be submitted: SS, MJH BW. All authors read and approved the final manuscript.

\section{Ethics approval and consent to participate}

The Faculty of Medicine Universitas Indonesia Research Ethics Committee and the internal review board of Pondok Indah Hospital approved this study.

\section{Consent for publication}

Not applicable.

\section{Competing interests}

The authors declare that they have no competing interests.

\section{Publisher's Note}

Springer Nature remains neutral with regard to jurisdictional claims in published maps and institutional affiliations.

\section{Author details}

${ }^{1}$ Tropical and Infectious Diseases Consultant, Pondok Indah Hospital, Jakarta, Indonesia. ${ }^{2}$ Division of Tropical and Infectious Diseases, Department of Internal Medicine, Faculty of Medicine Universitas Indonesia, Cipto Mangunkusumo National Hospital, Jakarta, Indonesia. ${ }^{3}$ Department of Radiology, Pondok Indah Hospital, Jakarta, Indonesia. ${ }^{4}$ Department of Clinical Pathology, Pondok Indah Hospital, Jakarta, Indonesia.

\section{Received: 21 March 2017 Accepted: 15 February 2018}

Published online: 23 February 2018

\section{References}

1. Srikiatkhachorn A. Plasma leakage in dengue haemorrhagic fever. Thromb Haemost. 2009;102(6):1042-9.

2. Lye DC, Chan M, Lee VJ, Leo YS. Do young adults with uncomplicated dengue fever need hospitalisation? A retrospective analysis of clinical and laboratory features. Singap Med J. 2008;49(6):476-9.

3. SEARO W. Comprehensive guidelines for prevention and control of dengue and dengue haemorrhagic fever; 2011.

4. Suwarto S, Nainggolan L, Sinto R, Effendi B, Ibrahim E, Suryamin M, et al. Dengue score: a proposed diagnostic predictor for pleural effusion and/or ascites in adults with dengue infection. BMC Infect Dis. 2016;16:322.

5. Abu-Assi E, Garcia-Acuna JM, Pena-Gil C, Gonzalez-Juanatey JR. Validation of the GRACE risk score for predicting death within 6 months of follow-up in a contemporary cohort of patients with acute coronary syndrome. Rev Esp Cardiol. 2010;63(6):640-8.

6. Rapsang AG, Shyam DC. Scoring systems in the intensive care unit: a compendium. Indian J Crit Care Med. 2014;18(4):220-8.

7. TDR/WHO. Dengue: guidelines for diagnosis, treatment, prevention and control. Geneva: WHO Press; 2009

8. Yadav SP, Sachdeva A, Gupta D, Sharma SD, Kharya G. Control of massive bleeding in dengue hemorrhagic fever with severe thrombocytopenia by use of intravenous anti-D globulin. Pediatr Blood Cancer. 2008;51(6):812-3.

9. Gan VC, Lye DC, Thein TL, Dimatatac F, Tan AS, Leo YS. Implications of discordance in world health organization 1997 and 2009 dengue classifications in adult dengue. PLoS One. 2013:8(4):e60946.

10. Collins GS, Ogundimu EO, Altman DG. Sample size considerations for the external validation of a multivariable prognostic model: a resampling study. Stat Med. 2016;35(2):214-26.
11. Kuo HJ, Lee IK, Liu JW. Analyses of clinical and laboratory characteristics of dengue adults at their hospital presentations based on the World Health Organization clinical-phase framework: emphasizing risk of severe dengue in the elderly. J Microbiol Immunol Infect. 2017;

12. Michels M, Sumardi U, de Mast Q, Jusuf H, Puspita M, Dewi IM, et al. The predictive diagnostic value of serial daily bedside ultrasonography for severe dengue in Indonesian adults. PLoS Negl Trop Dis. 2013;7(6):e2277.

13. Clinical Manifestations KS. Management of Dengue/DHF/DSS. Trop Med Health. 2011;39(4 Suppl):83-7.

14. Guilarde AO, Turchi MD, Siqueira JB Jr, Feres VC, Rocha B, Levi JE, et al. Dengue and dengue hemorrhagic fever among adults: clinical outcomes related to viremia, serotypes, and antibody response. J Infect Dis. 2008; 197(6):817-24.

15. Parikh R, Mathai A, Parikh S, Chandra Sekhar G, Thomas R. Understanding and using sensitivity, specificity and predictive values. Indian J Ophthalmol. 2008;56(1):45-50.

16. Maxim LD, Niebo R, Utell MJ. Screening tests: a review with examples. Inhal Toxicol. 2014;26(13):811-28.

17. Yacoub S, Wills B. Predicting outcome from dengue. BMC Med. 2014;12:147

18. Jayashree K, Manasa GC, Pallavi P, Manjunath GV. Evaluation of platelets as predictive parameters in dengue fever. Indian J Hematol Blood Transfus. 2011:27(3):127-30

19. Srikiatkhachorn A, Gibbons RV, Green S, Libraty DH, Thomas SJ, Endy TP, et al. Dengue hemorrhagic fever: the sensitivity and specificity of the world health organization definition for identification of severe cases of dengue in Thailand, 1994-2005. Clin Infect Dis. 2010:50(8):1135-43.

20. Fernando S, Wijewickrama A, Gomes L, Punchihewa CT, Madusanka SD, Dissanayake $\mathrm{H}$, et al. Patterns and causes of liver involvement in acute dengue infection. BMC Infect Dis. 2016;16:319.

21. Jayaratne SD, Atukorale V, Gomes L, Chang T, Wijesinghe T, Fernando S, et al. Evaluation of the WHO revised criteria for classification of clinical disease severity in acute adult dengue infection. BMC Res Notes. 2012;5:645.

22. Gan VC. Dengue: moving from current standard of care to state-of-the-art treatment. Curr Treat Options Infect Dis. 2014;6(3):208-26.

23. Suwarto S, Tedjo Sasmono R, Sinto R, Ibrahim E, Suryamin M. Association of Endothelial Glycocalyx and Tight and Adherens junctions with severity of plasma leakage in dengue infection. J Infect Dis. 2017:215(6):992-9.

24. Thein TL, Gan VC, Lye DC, Yung CF, Leo YS. Utilities and limitations of the World Health Organization 2009 warning signs for adult dengue severity. PLoS Negl Trop Dis. 2013;7(1):e2023.

25. Trung DT, le $\pi T$, Hien TT, Hung NT, Vinh NN, Hien PT, et al. Liver involvement associated with dengue infection in adults in Vietnam. Am J Trop Med Hyg. 2010;83(4):774-80.

26. Sam SS, Omar SF, Teoh BT, Abd-Jamil J, AbuBakar S. Review of dengue hemorrhagic fever fatal cases seen among adults: a retrospective study. PLoS Negl Trop Dis. 2013;7(5):e2194.

27. Flamand C, Fritzell C, Prince C, Abboud P, Ardillon V, Carvalho L, et al. Epidemiological assessment of the severity of dengue epidemics in French Guiana. PLoS One. 2017;12(2):e0172267.

28. Huy NT, Van Giang T, Thuy DH, Kikuchi M, Hien TT, Zamora J, et al. Factors associated with dengue shock syndrome: a systematic review and metaanalysis. PLoS Negl Trop Dis. 2013;7(9):e2412.

\section{Submit your next manuscript to BioMed Central and we will help you at every step:}

- We accept pre-submission inquiries

- Our selector tool helps you to find the most relevant journal

- We provide round the clock customer support

- Convenient online submission

- Thorough peer review

- Inclusion in PubMed and all major indexing services

- Maximum visibility for your research

Submit your manuscript at www.biomedcentral.com/submit
Biomed Central 